\title{
Virtual Tutoring and Counseling in Schools
}

\author{
Esteban Vázquez Cano ${ }^{1}$ and Eloy López Meneses ${ }^{2}$ \\ ${ }^{1}$ Department of Didactics and School Organization, National Distance Education University, \\ C/ Juan del Rosal 14, 28040 Madrid, Spain \\ ${ }^{2}$ Area of School Organization and Didactics, Faculty of Social Sciences, Pablo de Olavide University, \\ Carretera de Utrera Km 1, 41013 Seville, Spain
}

Correspondence should be addressed to Esteban Vázquez Cano, evazquez@edu.uned.es

Received 27 April 2012; Accepted 31 May 2012

Academic Editors: S. Cessna, U. Moore, R. Pasnak, and P. A. Prelock

Copyright (C) 2012 E. Vázquez Cano and E. López Meneses. This is an open access article distributed under the Creative Commons Attribution License, which permits unrestricted use, distribution, and reproduction in any medium, provided the original work is properly cited.

\begin{abstract}
This paper is a report on the findings of a study conducted on ten primary and secondary schools in Spain where we evaluated how digital tools can contribute to reinforce and develop new ways of tutoring and counseling. The research shows how many counseling functions can be highly enhanced with the use of virtual tools, that is, academic planning, career postsecondary planning, tutoring, counseling, and personal-social development. One of the most important school counselor's roles is to coordinate resources and services to best assist students and families in fulfilling their needs. Virtual tutoring and counseling through the development of virtual communities are key strategies to better connect with groups—students, parents, administrators, teachers, and others_as part of comprehensive developmental tutoring and counseling programs. Indeed, effective school counseling programs are a collaborative effort among many important groups of people whom digital tools help significantly.
\end{abstract}

\section{Introduction}

The educational activity has always had a dual function: on one hand, it has dealt with the transmission of knowledge, education in values, norms, and attitudes, and, on the other hand, it has always done a specific task to help the student, providing individualized attention and being concerned about the personal circumstances in order to support decisions about his/her future. Vázquez Cano et al. [1] consider that educational guidance serves the personal character and integrity of the teaching because real people are educated with particular individual characteristics [2]. Since the inception of the profession of school counseling, the role has been redefined and modernized, oftentimes to meet the needs of a changing society or in response to social events $[3,4]$. School counselors must work cooperatively with other individuals and organizations to promote the academic career and personal/social development of students $[5,6]$. Creating and facilitating virtual communities with information and communication technologies (ICT) can significantly increase a school counselor's ability to effectively provide a collaborative environment [7]. The remainder of this paper focuses on the nature of virtual communities, including advantages and disadvantages, and digital resources that school counselors can implement to begin building their own virtual communities at little or no cost. A virtual tutor establishes a human relationship with a virtual student and his/her family; both require more resources to establish a warm communication between school and houses $[8,9]$.

The tutoring and counseling are the responsibility of not only the tutor, but also all teachers who have responsibility for a particular group of students [10]. The school has collegial institutional responsibilities shared by the faculty and in particular by the management team. The orientation and tutorial plans are included in the educational project of the school and should be encouraged and facilitated by the management team. In any school, the team manager must take responsibility for creating conditions that favor, in the framework of the educational project, the development of the psychology counseling and tutorial intervention. Thus, the principal is ultimately responsible for that guidance 
as an integral part of educational opportunities that can contribute to achieve the ultimate goal of education: the personal development of students.

In addition to the necessary involvement and coordination of all the teaching staff in the planning and development of the tutorial and guidance programs with strong support of the management team, qualified schools need structures to ensure the performance of many tutoring functions and integrate new communication and participation channels offered by the network to perform them.

\section{Information and \\ Communication Technologies (ICTs) for Developing Virtual Guidance and Counseling in Schools}

The full development of tutoring and counseling functions is so broad, and sometimes so complex, that teachers may feel overwhelmed by their responsibilities. It is not easyor simply not possible- that a single teacher could meet all kinds of educational needs that are in schools [11]. This is the reason why schools that integrate students with special educational needs incorporate support teachers. This is the reason, too, by which new resources are needed and ICT plays a decisive role. In these and other aspects, ICTs feature as powerful instruments of communication and interaction among all members of school communities [12]. In general, communities could be understood as "self-organizing groups of individuals organized around a perceived need to satisfy a shared interest or set of interests by cooperating" [13]. In order to capture the mediated nature of interactions, Internet-based communities are most commonly referred to as virtual communities (VCs), in which closeness is based more on shared interest than shared social characteristics such as socioeconomic status or gender [14]. Lesser et al. [15] note that "participation in social communities shapes our experience and it also shapes those communities, the transformative potential goes both ways." When computer networks link people as well as machines, they become social networks, which we call computer-supported social networks (CSSNs). Members of virtual community want to link globally with kindred souls for companionship, information, and social support from their homes and workstations. One study found that work groups using computer-mediated communication (CMC) have a higher level of communication than those that do not [16], while another found that heavy CMC use reduces face-to-face and telephone communication [17]. A self-organization is formed when actors have the capacity to act and make choices, which creates social structures that enable and constrain action [18]. The school is shaped as a heterogeneous group of people where participation appears as one of the dynamics needed to assign the name of community. To develop a real community there must be interaction $[19,20]$. Interactive educational networks support teaching duties from the perspective of a participatory and collaborative community. The Universal Declaration of Human Rights [21] recognizes in its Article 27.1 that: "Everyone has the right freely to participate in the cultural life of the community, to enjoy the arts and to share in scientific advancement and its benefits."

This participation appears not as a technological fashion but as a social and pedagogical need [22]. Nowadays, to carry out this in school, it is eminently necessary to implement participatory structures in which all members work together, participate, and feel active members of the school community [23]. Developing school communities in which virtual tutoring and counseling are developed is a necessary goal but difficult to achieve if we are not able to integrate and effectively channel to promote active participation of families and teachers. Technological tools as chat, forums, blogs, and so forth arise as a powerful resource that helps to make an effective and quality networked tutoring community, especially when these tools are embedded in the improvement plans agreed and planned from the reality of education in schools [24]. In addition to these benefits, it would be also desirable to consider more general principles to make effective virtual tutoring and counseling in schools.

(i) It must be voluntary, so it can be freely accepted by each person and as a result of a process of reflection on the positive aspects. Educational networks based on the interactivity of digital resources enable a free and voluntary participation at any time. There is a minimal need for training, which can be provided by the school itself with the administration support.

(ii) It must be integrated into the educational philosophy, which distinguishes, in a given period, the planning of a particular community. It will serve in any case the uniqueness of a learning environment and global education that connects harmoniously with a school experiences. ICT encourages a collaborative and participative learning environment, harmonizing different academic and extracurricular activities.

(iii) It must be as direct as possible, in an effort to exploit the educational knowledge and experience of various community members. ICT involves families in the teaching-learning process from the social sphere, joining in the educational process, parents and students.

Thus, the school, and its primary function of providing compulsory education, also promotes a dynamic integration with the community. There are four attributes of online communities: policies, purposes, people, and software; these attributes are grouped under two concepts, sociability and usability. Despite the contested nature of the concept [25], there is agreement that people in online communities are engaging in persistent conversations and interactions in online information spaces. There is also agreement that ICTs play important roles in these communities [26]. As online communities proliferate in the Web 2.0 environment, researchers are asking how such communities are formed, sustained, changed over time, and are using a variety of theoretical and methodological tools to study them, seeking to understand their trajectories and dynamics [27]. One feature common to these communities is that they are digitally mediated and persistent settings within which 
people routinely interact, constituting and reconstituting their social worlds over time [28].

\section{Research Questions}

Using a qualitative and quantitative multicase study design, the following questions were addressed.

(1) How do educational communities rate the use of digital resources for promoting virtual tutoring and counseling?

(2) What digital resources could help to develop tutoring and counseling experiences?

(3) To what extent did collaboration occur mediated by ICT among members of educational communities to develop tutoring and counseling?

\section{Method}

The purpose of this multicase study research was to investigate the ICT strategies in schools to develop tutoring and counseling functions and to better understand and describe the types of collaboration among all members of educational communities in the development of these key functions. The purpose of phenomenological research is not to obtain generalizations but to describe in detail the breadth and depth of individual experience with the phenomenon and the meaning structures of such experience [29]. Stake [30] pointed out that multicase studies are "studies of particularization more than generalization." This study was delimited to ten schools in Spain. Stake emphasized the need for commonality of individual cases that can be categorically bound together. Stake refers to the group, category, or phenomenon as a "quintain" [30]. The commonality of this particular quintain was schools that were recognized for their leadership positions in Toledo (Spain) in both educational results and communities programs. This multicase study [31,32] includes data collected from interviews, observations, field notes, participation in forums, and electronic messages. For a period of six days in each school, five key participants acted as coresearchers by providing feedback and collaborating in inductive analysis of the data. The study covers a wide range of tasks of different nature; to be resolved effectively, they have required the use of various methods. Along the same methods were used both quantitative and qualitative, whereas both are complementary and can benefit from each other $[33,34]$. Thus, we have taken a qualitative approach in trying to understand the behavior of all members of educational communities involved in the monitoring process.

4.1. Data Collection and Analysis. The multicase study was carried out during 2011 in ten schools in the province of Toledo (Spain) with different sociocultural and economic contexts with the characteristics outlined in Table 1.

Our key informants and techniques in the sample were described as in Table 2.

Data were collected over two months from individual participant interviews, questionnaires, study group, meeting notes, participant reflections, and the researcher's field notes and reflections. Detailed field notes and reflections were maintained on a daily basis, along with an audit trail of when and how the data were collected and analyzed. Carefully constructed interview questions about a teacher's professional development experiences in tutoring and counseling were developed. All interviews were prescheduled, tape-recorded, and transcribed for accuracy. These techniques have an important complementary value, as the interviewer can understand and grasp what an informant thinks and believes, how he/she interprets his/her world and what meanings he/she uses and manages. By contrast, the observation allows us to precisely access the content, that is, the actions of the informants as they occur in their natural context of action. According to Kemmis and McTaggart [35] we consider that the observation serves to document the effects of critically informed action and seeks to achieve a reliable basis for reflection. Participant observation has been made by the education inspector monitoring the functioning of virtual tutoring and counseling systems. In this way, he/she can provide guidance and make appropriate recommendations or requirements necessary for the teachers. It can also help to promote good teaching practices all of which may result in improving the quality of education in schools. We also used a questionnaire to guide the interviews. Several authors of ethnographic research highlight the importance of the questionnaire, as Woods [36] indicating its relevance as a means to gather information for larger samples than those obtained through personal interviews or individualized sources. Also Kemmis and McTaggart [35] referred to relevance in that school communities can improve what they do by the findings of the questionnaire data that will enable appropriate treatment and reflections.

The questionnaire focuses on three areas.

Area 1. Monitoring and execution of tutoring and counseling tasks with ICT support.

Area 2. Digital communication among all members of the educational community.

Area 3. Advice, guidance, participation, and information with ICT.

The researcher reviewed the data and generated a list of more than five common data categories related to the participants' virtual tutoring and counseling experiences and collaborative activities with other teachers. Data were sorted into these categories and then analyzed within the framework of content, process, structure, and context to gain: (a) insights about the varied and unique contexts in which teachers develop tutoring and counseling, (b) a deeper understanding about the tutoring and counseling in schools in virtual environments, and (c) knowledge on the complex process of tutoring and counseling and collaboration in schools. As the researcher compared data in each category from case to case, similar to the stepby-step process described by Merriam [31], similarities and differences among the participants' experiences in one 
TABLE 1: School data.

\begin{tabular}{lccccc}
\hline & \multirow{2}{*}{ Primary schools } & High schools & $\begin{array}{c}\text { Private with concert } \\
\text { Primary schools }\end{array}$ & $\begin{array}{c}\text { Private with concert High } \\
\text { schools }\end{array}$ & Private schools \\
\hline City & 2 & 2 & 1 & 1 & Total \\
Rural & 1 & 1 & 1 & 0 & 1 \\
Number of students & 953 & 1167 & 957 & 657 & 0 \\
\hline
\end{tabular}

TABLE 2: Key informants and techniques.

\begin{tabular}{lcccccccc}
\hline & \multicolumn{2}{c}{ Teachers } & \multicolumn{2}{c}{ Supervisors } & \multicolumn{2}{c}{ Students } & \multicolumn{2}{c}{ Families } \\
& Male & Female & Male & Female & Male & Female & Male & Female \\
\hline Questionnaires & 32 & 31 & 11 & 5 & 25 & 25 & 35 & 34 \\
Open questions & 22 & 21 & 10 & 3 & 20 & 20 & 30 & 30 \\
Semistructured individual interviews & 20 & 20 & 11 & 5 & 20 & 20 & 20 & 20 \\
\hline
\end{tabular}

or both of the tutoring and counseling activities became evident. The researcher then synthesized data into a common theme about which tools 2.0 better help to support tutoring and counseling in schools. Several strategies were used to check the accuracy of the findings, including peer debriefing, member checking, and the use of rich description [29]. The cases were peer-reviewed by a faculty member familiar with the project and educational inspection services, for feedback on the comprehensiveness of the cases and the literature regarding issues found within each case. In addition, each participant was given the opportunity to review his or her case write-up and provide feedback regarding the accuracy of the data interpretations. Feedback from peer faculty and participants was considered carefully during the on-going analysis, and appropriate changes and additions were made in the final analysis process. Rich descriptions and detailed excerpts of data for each case were used to engage the readers to draw their own conclusions about the teachers' learning and collaboration in the professional development experiences [29-31]. The data from the various monitoring techniques are triangulated in order to increase the validity of the results of the study by purification of the inherent shortcomings of a single method of data collection and control of the supervisor's personal bias. According to Flick [37] the "triangulation" of perspectives increases attention to the phenomenon under study. We also created a forum for discussion between families and teachers for what another questionnaire was used to measure social network variables. The forum participants participated for three weeks with 27 families and 15 teachers and produced 234 messages. The forum had three fundamental interest areas as questionnaires ((1) monitoring and execution of tutoring and counseling tasks with ICT support, (2) digital communication among all members of the educational community, and (3) advice, guidance, participation, and information with ICT). Answers to the questions asked in the forum were analyzed according to three items that characterize virtual tutoring at schools: affective, interactive, and cohesive relationships. We analyzed the transcription of the messages according to the categories [38].

\section{Findings}

The purpose of this multicase study research was to investigate the ICT strategies in schools to develop tutoring and counseling functions and to better understand and describe the types of collaboration among all members of educational communities in the development of these key functions. Tables 3, 4, 5, and 6 provide answers to our research questions (1) and (3) and show the appreciation of the different members of educational communities about the inclusion of digital resources to develop tutoring and counseling function in schools and improve actions. Figures 1 and 2 answer our research question (2) and provide a diagram on the tools 2.0 with better support for tutoring and counseling function in schools.

We were concerned about the assessment that could be undertaken by the two groups most sensitive for the development of tutorial functions (families and students). We present their assessment of digital resources most useful for the development of virtual tutoring and counseling. Results are obtained in Figures 1 and 2.

The forums and email are the most valued tools and easy to use for the development of inquiries from families; besides blogs are also greatly appreciated to post and retrieve information. These three tools give confidence to families just to ask for information and request assistance, as well as to get information on relevant aspects of mentoring and guidance of their children. It is so important to develop virtual parents counseling with various topics that help to perform more collaborative education.

Social networks along with blogs and forums are best rated as web 2.0 tools for guidance and mentoring in the school by the students. They find these digital tools fast and attractive to interact with the guidance departments, teachers, and other students or participate in chats or forums related to these topics in blogs.

\section{Discussion}

The research results show that the profits more highly rated in virtual tutoring and counseling by families, students, and teachers are as follows. 
TABLE 3: (Area 1) Monitoring and execution of tutoring and counseling tasks with ICT support.

(1) What action based on ICT means an improvement of tutoring and counseling functions?

$\begin{array}{lccc} & \text { Teacher } & \text { Supervisor } \\ \text { (a) Virtual information and participation (forums) } & \text { Family } & 72 \% & 90 \% \\ \text { (b) Communication of absences } & 65 \% & 90 \% & 100 \% \\ \text { (c) Academic information for families } & 97 \% & 79 \% & 88 \% \\ \text { (d) Virtual conversations (chats and videoconference) } & 89 \% & 69 \% & 87 \% \\ \text { (e) Digital agenda } & 85 \% & 77 \% & 93 \% \\ \text { (f) Electronic assessment information } & 91 \% & 74 \% & 99 \%\end{array}$

(2) How do you rate the inclusion of ICT in tutoring and counseling duties?

\begin{tabular}{lccc} 
& Teacher & Supervisor \\
(a) Excellent & Family & $75 \%$ & $80 \%$ \\
(b) Very good & $81 \%$ & $10 \%$ & $9 \%$ \\
(c) Good & $5 \%$ & $5 \%$ & $6 \%$ \\
(d) Regular & $4 \%$ & $10 \%$ & $5 \%$ \\
(e) Poor & $10 \%$ & $0 \%$ & $0 \%$ \\
\hline
\end{tabular}

TABle 4: (Area 2) Digital communication among all members of the educational community for promoting tutoring and counseling.

(1) What action based on ICT means improved tutoring and counseling among members of the educational community?

\begin{tabular}{lccc} 
& Teacher & Supervisor \\
(a) E-mail & $75 \%$ & $67 \%$ & $78 \%$ \\
(b) Networking & $95 \%$ & $89 \%$ & $100 \%$ \\
(c) Virtual Tutor & $40 \%$ & $54 \%$ & $78 \%$ \\
(d) Virtual Agenda & $67 \%$ & $57 \%$ & $69 \%$ \\
\hline
\end{tabular}

(2) How do you rate the inclusion of ICT in tutoring and counseling between members of the educational community?

\begin{tabular}{lccc} 
& Family & \multicolumn{2}{c}{ Teacher } \\
(a) Excellent & $71 \%$ & $45 \%$ & $75 \%$ \\
(b) Very good & $9 \%$ & $15 \%$ & $9 \%$ \\
(c) Good & $10 \%$ & $10 \%$ & $6 \%$ \\
(d) Regular & $9 \%$ & $12 \%$ & $6 \%$ \\
(e) Poor & $1 \%$ & $18 \%$ & \\
\hline
\end{tabular}

TABle 5: (Area 3a) Advice, guidance, participation, and information with ICT.

Families (From 1 to 6 ; 6 being the highest rate)

\begin{tabular}{|c|c|c|c|c|c|c|}
\hline \multirow{2}{*}{$\begin{array}{l}\text { (1) Rate the use of virtualized tutoring and counseling systems in the development } \\
\text { of educational community counseling, guidance, and/or virtual information. }\end{array}$} & 1 & 2 & 3 & 4 & 5 & 6 \\
\hline & $0 \%$ & $2 \%$ & $26 \%$ & $21 \%$ & $49 \%$ & $2 \%$ \\
\hline \multirow{2}{*}{$\begin{array}{l}\text { (2) Rate the use of virtualized tutoring and counseling systems in the development } \\
\text { of personal and professional competences. }\end{array}$} & 1 & 2 & 3 & 4 & 5 & 6 \\
\hline & $0 \%$ & $1 \%$ & $18 \%$ & $21 \%$ & $25 \%$ & $34 \%$ \\
\hline \multirow{2}{*}{$\begin{array}{l}\text { (3) Rate the use of virtualized tutoring and counseling systems in your expectations } \\
\text { about the school. }\end{array}$} & 1 & 2 & 3 & 4 & 5 & 6 \\
\hline & $0 \%$ & $3 \%$ & $23 \%$ & $25 \%$ & $38 \%$ & $11 \%$ \\
\hline
\end{tabular}

TABle 6: (Area 3b) Advice, guidance, participation, and information with ICT.

Teachers (From 1 to 6 ; being 6 the highest rate)

\begin{tabular}{|c|c|c|c|c|c|c|}
\hline \multirow{2}{*}{$\begin{array}{l}\text { (1) Rate the use of virtualized tutoring and counseling systems in the development } \\
\text { of educational community counseling, guidance, and/or virtual information. }\end{array}$} & 1 & 2 & 3 & 4 & 5 & 6 \\
\hline & $8 \%$ & $6 \%$ & $16 \%$ & $20 \%$ & $30 \%$ & $20 \%$ \\
\hline \multirow{2}{*}{$\begin{array}{l}\text { (2) Rate the use of virtualized tutoring and counseling systems in the development } \\
\text { of personal and professional competences. }\end{array}$} & 1 & 2 & 3 & 4 & 5 & 6 \\
\hline & $6 \%$ & $8 \%$ & $10 \%$ & $21 \%$ & $25 \%$ & $30 \%$ \\
\hline \multirow{2}{*}{$\begin{array}{l}\text { (3) Rate the use of virtualized tutoring and counseling systems in your expectations } \\
\text { about the school. }\end{array}$} & 1 & 2 & 3 & 4 & 5 & 6 \\
\hline & $0 \%$ & $3 \%$ & $23 \%$ & $25 \%$ & $38 \%$ & $11 \%$ \\
\hline
\end{tabular}




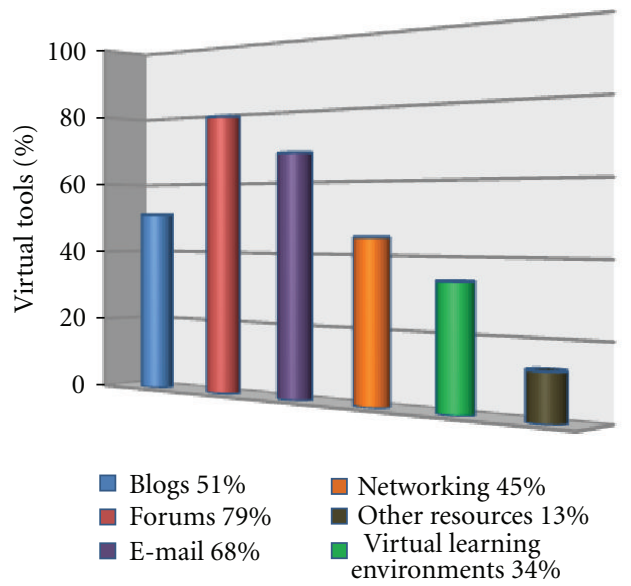

Figure 1: Web 2.0 tools most valued for virtual tutoring and counseling by families.

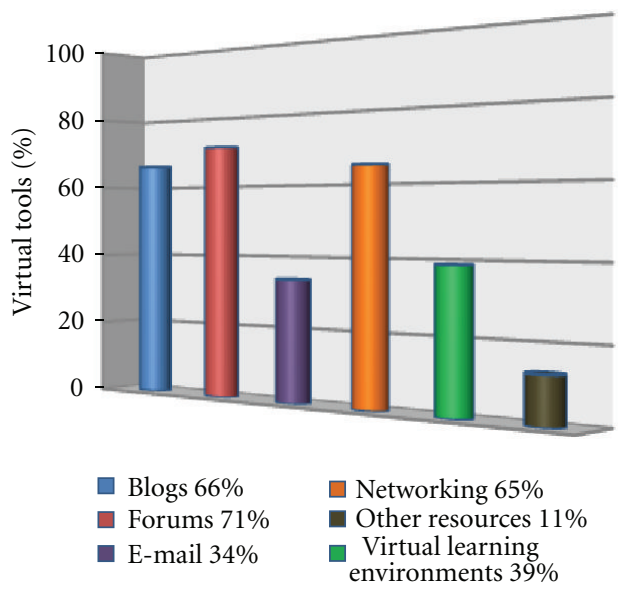

Figure 2: Web 2.0 tools more used for virtual tutoring and counseling by students.

(i) It is an activity where people and information can be accessed anytime and anywhere.

(ii) Members of the educational communities can connect to orchestrate "brainstorming sessions" and a wide range of cultural and tutoring activities.

(iii) It can contribute to overall more effective problem solving and decision-making.

(iv) It can foster connections with others of different racial, ethnic, and economic backgrounds, which, without the Internet, would probably not occur.

The main tutoring and counseling functions that significantly improve with the use of an online community with digital resources are the following.

\section{Students Interviews}

(i) Promote integration and participation of students in their group and in the life of the school and offer help and support especially to students with educational needs, developing participatory and peaceful attitudes ( $n: 28 / 70 \%)$.

(ii) Advise on the promotion or graduation, detecting learning difficulties and special needs, organizing support measures, and monitoring them from collaborative work between teachers and families $(n$ : $31 / 77.5 \%)$.

(iii) Prevent risk or possible occurrence of learning disabilities, developing different strategies: improving motivation, attention, reading comprehension, study skills, metacognitive strategies for learning, and so forth (n: 26/65\%).

(iv) Facilitate decision-making regarding academic and career path, promoting vocational maturation processes. This assistance will be especially necessary in times of decision-making and change of school or educational modality ( $n: 29 / 72.5 \%)$.

Families Interviews

(i) Promote collaboration, communication, and family involvement in school life, developing cooperation and establishing close relationships ( $n: 37 / 61.6 \%)$.

(ii) Provide information about evaluation criteria, promotion, and certification, as well as the learning process of their children, to assume a responsible and collaborative education ( $n: 38 / 77.5 \%)$.

(iii) Guide families and promote their cooperation in the work of academic and professional guidance, to facilitate decision-making ( $n: 39 / 65 \%)$.

\section{Teachers and Supervisors Interviews}

(i) Coordinate guidance from the different areas by chaining tutoring activity in the work of the teaching departments and enhancing the participation of all teachers ( $n: 41 / 73.2 \%)$.

(ii) Promote cross-curricular themes, interdisciplinary projects, participation in extracurricular activities related to academic and professional guidance and training ( $n: 38 / 67.8 \%)$.

(iii) Offer relationships with other schools, encouraging collaboration in academic or occupational orientation of students, as well as the employment of those who begin to work ( $n: 35 / 62.5 \%)$.

(iv) Maintain relationships with other institutions and associations (health center, city hall, departments, schools, universities, trade unions, etc.) to plan and develop coordinated educational activities ( $n$ : 37/ $66 \%)$.

In general, the use of these forms of tutoring and counseling promotes the students to improve their performance and understanding of the world around them, and among the most significant features, we can target the following. 
(a) Getting to Know Yourself. The student needs to stop, think, and reflect on how he/she works, feels, and reacts to relation to others and the world. Using the network as a means of socialization and a window to confront ideas and thoughts. Only the recognition and acceptance of what you are allows you to implement the necessary changes in your personal life, family, and school and thus you can continue the positive construction as a person.

(b) Assessing Their Qualities in a Virtual World. The students need to achieve their qualifications along with their efforts to change or modify what they are not satisfied with in the networked world.

(c) Acquiring a Global Vision. This lets he/she to take his/her reality and acts upon it. The information generally can be transmitted through the virtual counseling is much greater than occurs in person.

(d) Learning to Live in Society. The student must conform and adapt to the norms and rules of conduct and respect the rules of democratic coexistence. These rules have been transported into the world in a network that requires a basis of social behavior.

(e) Developing the Capacity for Dialoguing. This lets the student express what he/she thinks and feels and listens to what the other thinks and feels and it develops his/her capacity for empathy. The dialogue around social networks and digital communication must be understood from the principles of an open and respectful community.

For these purposes, almost all members of educational communities have argued and rated blogs, forums, and networking as the three virtual resources that are highly productive and useful to promote virtual tutoring and counseling.

\section{Conclusions}

The act of educating is not exercised only in relation to the teaching group and does not take place exclusively within the classroom, even more today with the potential of the networked world. In this sense, counseling is the process of helping an individual to know him/herself and the society he/she lives in, so he/she can achieve maximum internal organization and its further integration into society. The guidance and mentoring are an essential part of it. Therefore teaching practice should be approached from active tutoring and schools should allow this practice in an inclusive and accessible way to all members of educational communities. The use and development of social networks for tutoring and counseling in schools and their environments promote the following benefits.

(i) Universalization of communication, possible with all kinds of people around the world, peers, teachers, experts and so forth. (ii) Higher relationships (overcoming problems of distance and time synchronization) among teachers and families.

(iii) Environment for cooperative learning, shared knowledge construction, problem solving, and projects among counselors.

(iv) Globalization of information. Easy and inexpensive access to a huge flow of multimedia information (and updated) of all kinds.

(v) Development of interpersonal communication skills.

(vi) Enhancement of the development of independent learning strategies and skills recruitment, selection, evaluation and organization of information.

(vii) Universal diffusion of personal opinions and more possibilities for interdisciplinary and intercultural approach to the issues.

The ability to create an interactive network in which teachers, families, and students could share information and make inquiries in relation to mentoring, tutoring, and counseling of their children in all academic and social areas is a need for the twenty-first century school.

\section{Limitations and Implications for Future Research}

This multicase study is one brief glimpse into the different strategies to promote virtual tutoring and counseling in schools that can occur anytime anywhere for students and families. In this study, virtual tutoring and counseling were bound within the contexts of different schools with experience in these programs. The results help to show connections and common themes across; however, it is the readers' responsibility to take what they have learned and apply it to their situations, if they think it is applicable [31]. The implications from this study suggest that a virtual school counseling program is a necessity that schools should implement quickly and that schools should integrate into a virtual social network all teaching duties so they can develop them personally and on line.

\section{References}

[1] E. Vázquez Cano, M. L. Sevillano, and M. A. Méndez, Programar en Primaria y Secundaria, Pearson, Madrid, Spain, 2011.

[2] R. Schellenberg, The New School Counselor: Strategies for Universal Academic Achievement, Rowman Littlefield Education, Lanham, Md, USA, 2008.

[3] D. Beesley, "Teachers' perceptions of school counselor effectiveness: collaborating for student success," Education, vol. 125, pp. 259-270, 2004.

[4] J. J. Burnham and C. M. Jackson, "School counselor roles: discrepancies between actual practice and existing models," Professional School Counseling, vol. 4, no. 1, p. 41, 2000.

[5] American School Counselor Association, The Professional School Counselor and Cross/Multicultural Counseling (Position Statement), Alexandria, VA, USA, 1999. 
[6] P. C. Abney and C. D. Maddux, "Counseling and technology: some thoughts about the controversy," Journal of Technology in Human Services, vol. 22, no. 3, pp. 1-24, 2004.

[7] C. A. Dahir and C. B. Stone, The Transformed School Counselor, Brooks/Cole, Belmont, Calif, USA, 2nd edition, 2009.

[8] R. Halverson and A. Smith, "How new technologies have (and have not) changed teaching and learning in schools," Journal of Computing in Teacher Education, vol. 26, pp. 49-54, 2010.

[9] C. Murray, "Schools and social networking: fear or education?” Synergy Perspectives: Local, vol. 6, no. 1, pp. 8-12, 2008.

[10] S. B. Baker and E. R. Gerler, School Counseling for the TwentyFirst Century, Merrill Prentice Hall, Upper Saddle River, NJ, USA, 4th edition, 2004.

[11] D. Beesley, "Teachers' perceptions of school counselor effectiveness: collaborating for student success," Education, vol. 125, pp. 259-270, 2004.

[12] C. Holcomb-McCoy and S. F. Chen-Hayes, "Culturally competent school counselors: affirming diversity by challenging oppression," in Transforming the School Counseling Profession, B. T. Erford, Ed., Pearson, Boston, Mass, USA, 3rd edition, 2011.

[13] P. Baker and A. Ward, "Bridging temporal and spatial 'gaps': the role of information and communication technologies in defining communities," Information, Communication \& Society, vol. 5, no. 2, pp. 207-224, 2002.

[14] B. Wellman and M. Gulia, "Net surfers don't ride alone: virtual communities as communities," in Communities in Cyberspace, P. Kollock and M. Smith, Eds., University of California Press, Berkeley, Calif, USA, 1996.

[15] E. Lesser, E. M. Wenger, N. White, J. D. Smith, and K. Rowe, "Technology for communities: CEFRIO book chapter, 2000," in Communities of Practice: The Key to Knowledge Strategy, E. Wenger, Ed., 2005, http://www.ewenger.com/pub/index.htm.

[16] J. W. Hur and T. A. Brush, "Teacher participation in online communities: why do teachers want to participate in selfgenerated online communities of K-12 teachers?” Journal of Research on Technology in Education, vol. 41, no. 3, pp. 279303, 2009.

[17] T. Finholt, L. Sproull, and S. Kiesler, "Communication and performance in Ad Hoc task groups," in Intellectual Teamwork: Social and Technological Foundations of Cooperative Work, J. Galegher, R. E. Kraut, and C. Egido, Eds., pp. 291-325, Lawrence Erlbaum Associates, Hillsdale, NJ, USA, 1990.

[18] C. Murray, "Schools and social networking: fear or education?” Synergy Perspectives: Local, vol. 6, no. 1, pp. 8-12, 2008.

[19] C. A. Sink, "School counselors as accountability leaders: another call for action," Professional School Counseling, vol. 13, no. 2, pp. 68-74, 2009.

[20] S. Minocha, "A case study-based investigation of students' experiences with social software tools," New Review of Hypermedia and Multimedia, vol. 15, no. 3, pp. 245-265, 2009.

[21] The Universal Declaration of Human Rights, 1948, http:// www.un.org/en/documents/udhr/.

[22] D. D. Curtis and M. J. Lawson, "Exploring collaborative online learning," Journal of Asynchronous Learning Network, vol. 5, no. 1, pp. 21-34, 2001.

[23] E. Vázquez Cano and M. L. Sevillano García, Educadores en Red, Ediciones Académicas, Madrid, Spain, 2011.

[24] C. Jones, The Conditions of Learning in Networks, Kaleidoscope CSCL SIG, Lausanne, Switzerland, 2004.

[25] J. Preece and D. Maloney-Krichmar, "Online communities: focusing on sociability and usability," in Handbook of HumanComputer Interaction, J. A. Jacko and A. Sears, Eds., Lawrence Erlbaum Associates, London, UK, 2003.
[26] J. J. Burnham and C. M. Jackson, "School counselor roles: discrepancies between actual practice and existing models," Professional School Counseling, vol. 4, no. 1, p. 41, 2000.

[27] D. Churchill, "Educational applications of Web 2.0: using blogs to support teaching and learning," British Journal of Educational Technology, vol. 40, no. 1, pp. 179-183, 2009.

[28] G. A. Brigman, L. D. Webb, and C. Campbell, "Building skills for school success: improving the academic and social competence of students," Professional School Counseling, vol. 10, no. 3, pp. 279-288, 2007.

[29] J. W. Creswell, Research Design: Qualitative, Quantitative, and Mixed Methods Approaches, Sage Publications, Thousand Oaks, Calif, USA, 2nd edition, 2003.

[30] R. E. Stake, Multiple Case Study Analysis, Guilford Press, New York, NY, USA, 2006.

[31] S. B. Merriam, Qualitative Research and Case Study Applications in Education, Jossey-Bass Publishers, San Francisco, Calif, USA, 1998.

[32] R. E. Stake, The Art of Case Study Research, Sage Publications, Thousand Oaks, Calif, USA, 1995.

[33] C. S. Reichardt and T. D. Cook, "Beyond qualitative versus quantitative methods," in Qualitative and Quantitative Methods in Evaluation Research, T. D. Cook and C. S. Reichardt, Eds., pp. 7-32, Beverly Hills, Calif, USA, Sage, 1979.

[34] B. J. Biddlem and D. S. Anderson, "Theory, method, knowledge and research on teaching," in Handbook of Research on Teaching, M. C. Wittrock, Ed., pp. 230-252, McMillan, New York, NY, USA, 3rd edition, 1989.

[35] S. Kemmis and R. McTaggart, Eds., The Action Research Planner, Deakin University, Melbourne, Australia, 1988.

[36] P. Woods, Inside Schools: Ethnography in Educational Research, Routledge and Kegan Peter, New York, NY, USA, 1986.

[37] U. Flick, Triangulation, Eine Einführung, Deutscher Studien Verlag, Weinheim, Germany, 2004.

[38] L. Rourke, T. Anderson, D. R. Garrison, and W. Archer, "Assessing social presence in asynchronous text-based computer conferencing," Journal of Distance Education, vol. 14, no. 21, pp. 50-71, 2001. 

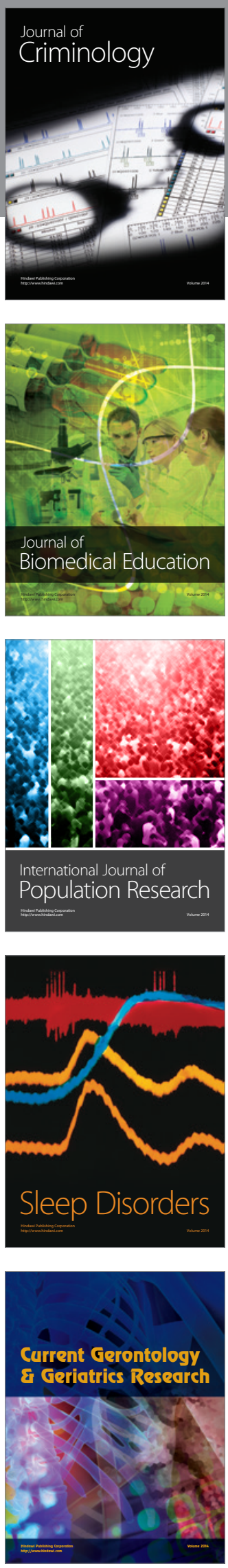
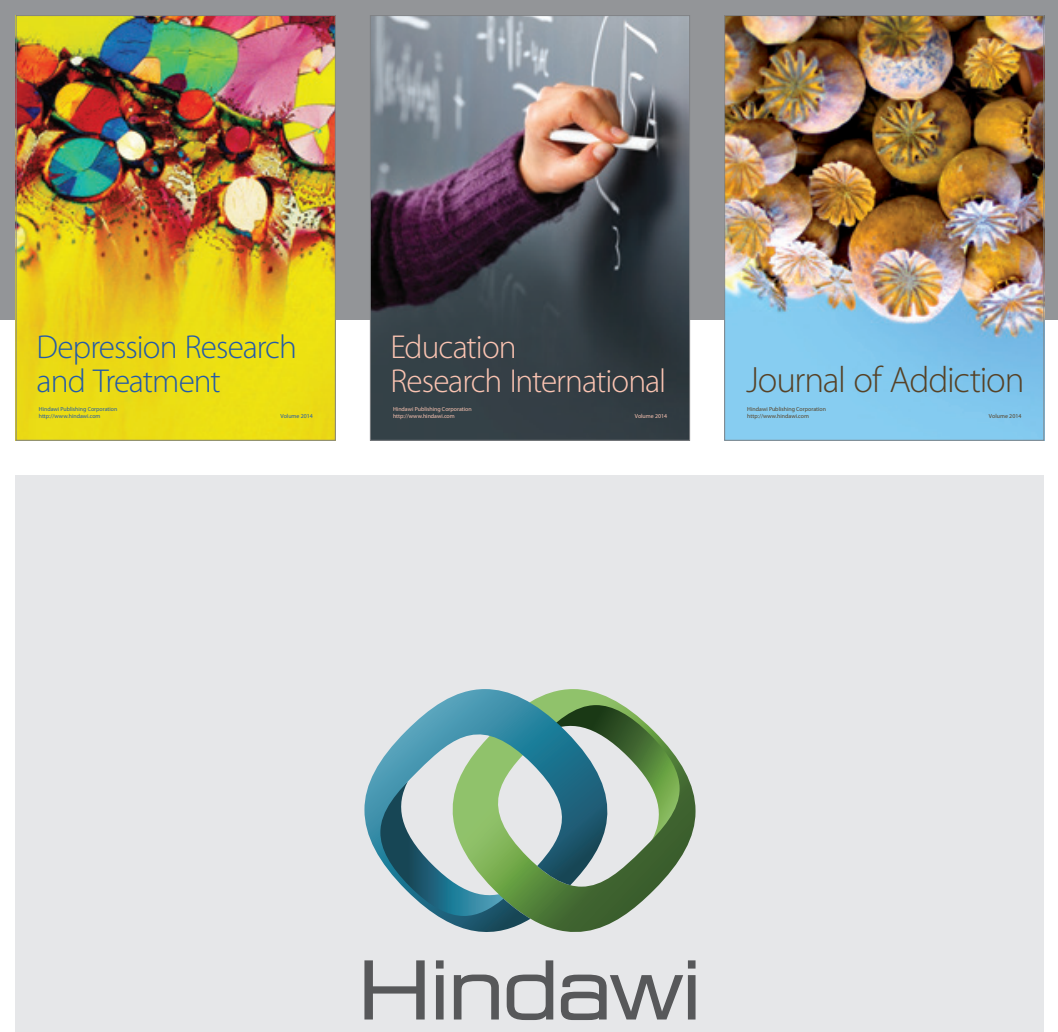

Submit your manuscripts at

http://www.hindawi.com

Child Development Research
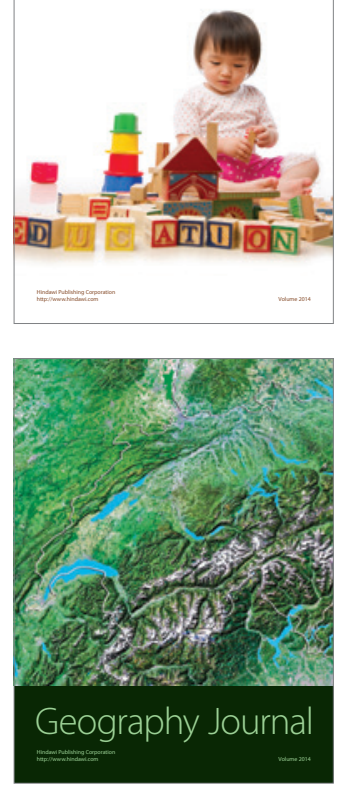

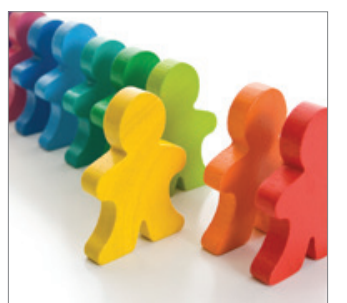

Autism

Research and Treatment
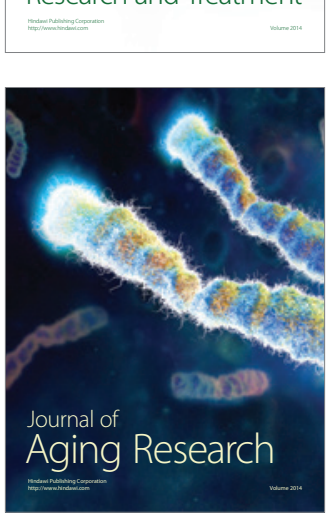
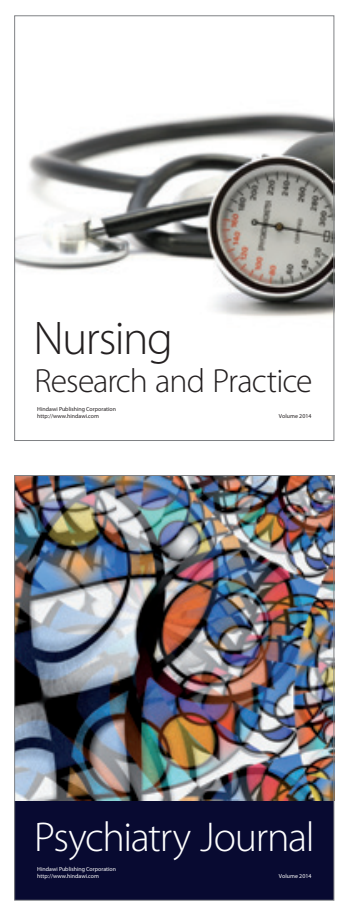
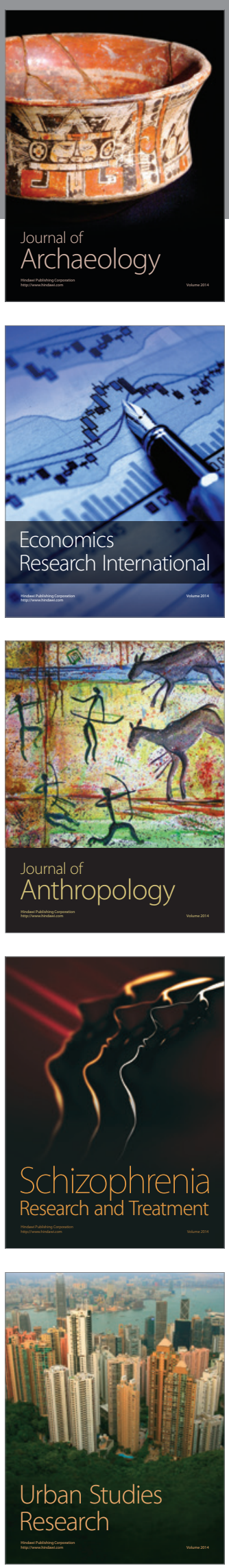